\title{
PAPEL ACTIVO DEL LENGUAJE EN LA PRAXIS DEL HOMBRE
}

\section{Ricardo Pérez Guzmán*}

Las conclusiones teóricas de Adam Schaff sobre el papel activo del lenguaje en sus relaciones con cl pensamiento, el conocimiento y la cultura, se apoyan en reflexiones argumentadas desde el punto de vista e los análisis filosóficos del lenguaje. Al análisis de estas relaciones llega el autor después de plantear la historia del problema en los tratados filosóficos, para analizar luego las premisas empíricas de la hipótesis Sapir - Worf que le permiten un acercamiento a los aspectos fundamentales de las relaciones entre el lenguaje y el proceso de cognición. El material que recoge el desarrollo de este proceso conceptual se reúne en el volumen Lenguaje y Conocimiento (1), cuyo último tratado "Lenguaje, conocimiento y cultura" se reseña a continuación.

La relación dinámica de este tratado con el resto del volumen es clara, tanto más cuanto que en él se hacen los planteamientos básicos sobre el papel activo del lenguaje en la actividad intelectual del hombre, recogiendo las conclusiones de los tratados que le anteceden en el orden estructural del volumen. Es por lo tanto evidente que el tratado se desarrolle partiendo del planteamiento del problema del papel activo del lenguaje que se puede concebir desde el punto de vista de su relación con el pensamiento, con el Conocimiento o con la cultura. El conocimiento se entiende como un tipo especial de pensamiento calificado, estableciéndose así su relación con el lenguaje equivalente a la que éste establece con el pensamiento. La cultura se analiza desde sus valores como actividad y como producto de dichas actividades. Continuando con la lógica interna del volumen, pensamiento, conocimiento y cultura, este tratado desarrolla las tres relaciones, centrándose en las relaciones lenguaje - conocimiento y lenguaje - cultura.

La primera relación que se establece es la de lenguaje - pensamiento. Las conclusiones logradas en los apartados anteriores le permiten al autor adoptar una premisa básica: el lenguaje siempre es pensamiento.

Además, el lenguaje presenta un significado tanto en forma de conceptos como en la representación que los acompaña, el lenguaje es por tanto, una abstracción de pensamiento, lenguaje que al mismo tiempo es pensamiento. La relación en sí, es una relación compleja, el pensamiento se expresa siempre en un lenguaje, sin él no es posible el conocimiento conceptual. A pesar de esta relación en que se ligan los dos elementos, no se identifican el uno con el otro. El papel activo del lenguaje en esta relación se concreta en el hecho de que no sea posible pensamiento conceptual sin lenguaje; además es el lenguaje la base social del pensamiento, actúa como mediador entre el hecho individual y su realización social, transmitiendo al mismo tiempo los conceptos elaborados socialmente. Por último, se plantea un factor muy importante, que es la actuación del lenguaje sobre los niveles dc abstracción y generalización del pensamiento, globalizando así esta relación dialéctica.

El lenguaje y el pensamiento son producto de la praxis humana. El proceso de pensamiento cuyo resultado es la descripción de la realidad es el conocimiento. Es por medio del conocimiento que se obtiene la información sobre hechos individuales y sus relaciones mutuas. En esta relación (lenguaje - conocimiento) adquiere mayor relevancia

\footnotetext{
* Licenciado en Lingüística y Literatura,Universidad Distrital; Magister en Lingüística y Literatura, Instituto Caro y Cuervo.
} 
la praxis, que establece una relación genética con el conocimiento; la vía del conocimiento comienza en la praxis. Pero esta relación se establece con base en el lenguaje que es el portador de las experiencias y el saber de las generaciones pasadas; constituyéndose en una praxis condensada que influye en nuestro conocimiento ante todo en la forma en que percibimos la realidad. Así, el lenguaje formado sobre la base de determinadas praxis sociales, se convierte en el creador de nuestra imagen de la realidad y permite la adopción de estructuras de acuerdo con el mundo objetivo y basadas en la praxis individual. El papel activo del lenguaje en el conocimiento se observa en la influencia que aquí se describe, porque al formarse el lenguaje empieza su función y su papel importante en la formación del conocimiento.

La constatación de este hecho llevó a posiciones extremas como el convencionalismo radical que hace depender la estructura del conocimiento del lenguaje y condiciona el proceso, llegando a postular la imposibilidad de transmisión y de traducción de Conocimientos que dependen de distintos sistemas lingüísticos. Pero la imagen de la realidad es la misma porque todos los hombres poseen las mismas aptitudes en el proceso de conocimiento y el destino biológico del género humano, que es común a la especie, se traduce en los universales lingüísticos. Otro factor importante que no es tenido en cuenta por el convencionalismo radical es el hecho de que el lenguaje no es invariable, sino por el contrario es un sistema dinámico en cuya evolución intervienen diversos motivos como la movilidad social y aún más el contacto entre culturas diferentes y el progreso de la civilización que borra cada vez más las diferencias de contenido lingüístico.

Por último, se plantea en el ensayo la relación lenguaje - cultura, siendo ésta última lo que piensa una comunidad dada y lo que hace. En este sentido, se presenta la relación lenguaje -cultura como una relación circular de influencia mutua que se puede tratar desde dos perspectivas: influencia de la cultura sobre el lenguaje e influencia del lenguaje sobre la cultura. Aquí se considera más apropiado el análisis que busca la influencia de la cultura de una sociedad en su lenguaje, que la posición de algunos lingüistas que excluyen tajantemente esa influencia. El aspecto que se desarrolló es el segundo, influencia del lenguaje sobre la situación y el desarrollo de la cultura. Al respecto se engloban elementos que se refieren a la influencia del lenguaje sobre procesos de pensamiento y de conocimiento; sobre los productos del pensamiento humano como ciencia, técnica, arte, etc; y sobre el mismo comportamiento humano y sus resultados.

La concepción en tomo al lenguaje que se expone en el trabajo relacionado sustenta un enfoque que ubica al lenguaje en una relación conceptual íntegra. La valoración del lenguaje como medio de transmisión de valores y conductas sociales que determinan el comportamiento de la persona, se complementa con la premisa de una visión generada por el lenguaje, que condiciona la contemplación del mundo. Se concluye que la perspectiva de la realidad está determinada por el papel activo del lenguaje en el conocimiento y por el desarrollo cultural, donde el lenguaje no es sólo un elemento sino que adquiere la función de co-creador. El lenguaje no es sólo instrumento, es objeto significativo.

\section{NOTAS}

1. SCHAFF, Adam, Lenguaje y Conocimiento, Grijalbo, México, 1984. Esta obra fue publicada originalmente con cl título "Jezik A. Poznanie" en la colección Teoría y Praxis, 1964, Panstwowe Wydawnictwo Naukowe, Varsovia. La traducción actual, a cargo de Mireia Bofill presenta tres partes, así: primera, historia del problema; segunda, premisas 
empíricas, y tercera, análisis del problema. Esta última Constituida por tres trabajos: lenguaje y pensamiento, lenguaje y realidad, y lenguaje, conocimiento y cultura. 